\title{
A ROTAÇÃO E A TRANSLAÇÃO DA TERRA: UM ESTUDO SOBRE O QUE SE ENSINA E O QUE SE VÊ
}

\author{
THE ROTATION AND THE TRANSLATION OF THE EARTH: \\ A STUDY OF WHAT IS TAUGHT AND WHAT IS SEE
}

ROTACIÓN Y TRANSLACIÓN DE LA TIERRA: UM ESTUDIO
SOBRE LO QUE SE ENSEÑA Y LO QUE VES

Michel Paschini Neto $^{\mathrm{I}}$
Maria Guiomar Carneiro Tommasiello

REsumo Os movimentos da Terra contrariam a verificação sensorial, que mostra um planeta imóvel. A transposição do que se observa para o modelo que se ensina é imprescindível ao ensino e aprendizagem da astronomia: a partir do que se vê ensinar o que não se vê. A presente pesquisa, de natureza qualitativa, tem por objetivo investigar os conhecimentos de professores de Ciências e de Física do ensino básico, a respeito dos movimentos terrestres. Foram aplicados questionários tipo Likert a 56 professores. Os resultados indicaram que os professores possuem pouco conhecimento a respeito dos modelos cosmológicos, da História da Astronomia e acerca da observação celeste, temas importantes para este estudo. Palavras-chave: Ensino de Astronomia; Movimentos da Terra; RotaÇão; Translação.

Abstract The Earth movements contradict the sensory feeling that shows an immobile planet. The transposition of what we observe concerned to the model that we teach is essential to the teaching and learning process of Astronomy: from what you see to teach what is not be seen. The present research, of qualitative nature aims to investigate the knowledge of the basic education teachers on the Science and Physics about the Hearth movements. Likert type questionnaires were applied to 56 teachers. The results indicate that they have little knowledge about the cosmological models, about the History of Astronomy and sky observation, important subjects for this study.

Key-words: Teaching of Astronomy; Earth movements; Rotation; Translation.

'Universidade Metodista de Piracicaba (UNIMEP), Piracicaba/SP - Brasil

"Universidade Metodista de Piracicaba (UNIMEP), Piracicaba/SP - Brasil 
RESUMEn Los movimientos de la tierra contradicen la verificación sensorial que muestra un planeta inmóvel. La transposición de lo que hemos observado para el modelo que enseñamos es esencial para el proceso de enseñanza-aprendizaje de la Astronomía: desde lo que ve enseñar lo que no se ve. La investigación, de naturaleza cualitativa, pretende investigar el conocimiento de los profesores de Ciencias y de Física de la educación básica acerca de los movimientos en tierra. Se aplicaron cuestionarios tipo Likert para 56 profesores. Los resultados indican que los profesores tienen poco conocimiento acerca de los modelos cosmológicos, sobre la Historia de la Astronomía y de la observación del cielo, temas importantes para este estúdio.

Palabras claves: La enseñanza de la Astronomía; Los movimientos de la tierra; La ROTACIÓN; LA TRASLACIÓN.

\section{INTRODUÇÃo}

O presente trabalho é um recorte da tese de doutoramento de um dos autores, que teve por objetivo geral investigar de modo qualitativo os conhecimentos de rotação e de translação da Terra que são abordados e priorizados no ensino de Astronomia na educação básica e como são trabalhados. Um dos objetivos específicos do trabalho mencionado foi mostrar quais são os conhecimentos dos professores da área de Ciências e da área de Física acerca da temática abordada enfatizando até onde a observação do céu, o referencial e os dados históricos são levados em conta no ensino e na aprendizagem desses conceitos.

O modelo heliocêntrico do sistema solar "é considerado o modelo científico "verdadeiro", que deve ser apresentado às crianças como um conhecimento básico da ciência" (ALBANESE et al., 1997, p. 573). É por meio desse modelo que se apresenta ao aluno que o movimento diário de leste para oeste dos astros acontece devido à rotação da Terra e que o movimento anual do Sol ocorre em decorrência da translação da Terra. Os fenômenos decorrentes desses dois movimentos terrestres são: o dia e a noite (rotação) e as estações do ano (translação), respectivamente.

As crianças elaboram de suas experiências cognitivas diárias, crenças e contatos com as outras pessoas um entendimento intuitivo dos movimentos e dos fenômenos astronômicos que as rodeiam (KIKAS, 1997; LIU, 2005; CHIRAS, VALANIDES, 2008), denominados de concepções alternativas (LANGUI, 2004) os quais, em geral, não estão de acordo com as explicações científicas e são difíceis de serem alterados (VOSNIADOU; BREWER, 1992).

As crianças chegam à escola com um leque de conhecimentos e de experiências perceptivas oriundas de observações e de interpretações da natureza (BAXTER, 1989; LIU, 2005). O que o aluno vê na natureza que se mostra tão diferente daquilo que o professor apresenta sobre os movimentos da Terra e acerca dos fenômenos do dia e da noite e das estações do ano?

O aluno vê, por exemplo, o Sol descrever um movimento da região leste para a região oeste do horizonte. Percebe que o Sol ao estar acima do horizonte é dia (período de claridade) e ao estar abaixo do horizonte é noite. $\mathrm{O}$ aluno pode ainda notar que no período de um 
ano o Sol descreve trajetórias em relação aos horizontes e às estrelas fixas que ocasionam o ciclo das estações do ano, já que há uma inclinação entre os círculos máximos da eclíptica (caminho aparente do Sol por entre as estrelas) e do equador celeste. É justamente essa inclinação que ocasiona as estações do ano por meio de uma visão topocêntrica.

Entretanto, na escola, ao contrário do que se observa na natureza, o aluno recebe a informação de que à medida que a Terra gira sobre si mesma, partes do planeta ficam em direção ao Sol e, dessa maneira, é dia nessas regiões e noite nas regiões opostas; e como a Terra orbita o Sol e seu eixo de rotação está inclinado em relação a uma reta perpendicular ao plano de sua órbita, ocorrem as estações do ano.

Do exposto, evidencia-se que existem duas concepções diferentes do fenômeno observado. Primeiramente, a do aluno que vê e sente diariamente a natureza à sua maneira e a do professor que ensina o conhecimento científico. Essa contradição entre aquilo que se observa na natureza e aquilo que é aprendido na sala de aula é um problema para a compreensão deste tema da Astronomia. Se os professores não souberem trabalhar essa contradição entre o que é observado e o que é aceito pela ciência hoje, eles, sem intenção, podem contribuir para a geração de concepções alternativas nos estudantes.

É importante deixar claro neste momento que quando se fala dos movimentos da Terra, é fundamental imaginar um observador no espaço, e isto exige um grau de imaginação e de abstração muito grandes. É necessário posicionar-se em vários pontos do espaço para se ter um entendimento correto dos movimentos terrestres que provocam os fenômenos do dia e da noite e das estações do ano. Essa visão espacial é difícil de ser adquirida, mesmo com um trabalho bem realizado em sala de aula. E para que o entendimento científico fique completo, é necessário que o professor, pelo menos, mencione a existência de provas de que a Terra está se movendo. Convém ressaltar que o dia e a noite e as estações do ano não são provas, apenas consequências dos movimentos terrestres, já que esses fenômenos podem ser explicados tanto do ponto de vista topocêntrico, quanto do ponto de vista heliocêntrico. As provas aceitas hoje, a aberração estelar (translação) e o Pêndulo de Foucault (rotação), por exemplo, são fenômenos demonstrados por meio de experimentos que corroboram suas veracidades. Além do mais, a aberração estelar e o Pêndulo de Foucault só podem ser explicados considerando a Terra em movimento.

Para se tentar corrigir esse problema, um caminho seria iniciar o tema dos movimentos da Terra e dos fenômenos deles resultantes justamente pela visão do observador, ou seja, que o professor apresente inicialmente esse tema pela visão topocêntrica. Dessa maneira, o aluno terá a oportunidade de observar o céu por seus próprios olhos, aprendendo a entender os movimentos e fenômenos celestes apresentando teorias para o que observam.

Essa abordagem é importante, pois pode contribuir para um entendimento mais completo dos temas aqui abordados. E por que essa premissa como hipótese?

Inicialmente, porque ninguém percebe os movimentos da Terra por estar na superfície terrestre. Também, por causa da relatividade do movimento que mostra, segundo Ben-Dov 
(1996, p. 24), que "o movimento aparente do Sol no céu significa não só que o Sol está em movimento relativo em relação à Terra, mas também que a Terra está em movimento relativo em relação ao Sol". Por esse motivo não faz sentido perguntar "qual dos dois, o Sol ou a Terra, está realmente em movimento, pois ambos os pontos de vista são admissíveis" (BEN-DOV, 1996, p. 33). Além do mais, há ainda o fato de que nosso senso comum "é -e sempre foi - medieval e aristotélico" (KOYRÉ, 2011, p. 202).

Castro e Schiel (2009, p. 95), por exemplo, consideram que no início da escolaridade, ao se apresentar os fenômenos do dia e da noite e das estações do ano, "não é importante ensinar à criança a rotação e a translação da Terra, mas sim o movimento diário do Sol, que servirá de base para a compreensão dos modelos sobre a forma e os movimentos da Terra e de sua relação com a Lua e o Sol".

É imprescindível, assim, para o ensino e a aprendizagem dos movimentos da Terra, a transposição do fenômeno que se observa para o modelo que se ensina, ou seja: a partir do que se vê ensinar o que não se vê. Essa prática requer dos professores um bom nível de conhecimento de história da Astronomia, de Física, dos modelos cosmológicos, do conceito de referencial e de experiências com práticas de observação do céu.

\section{Problema de investigação}

Trata-se de uma pesquisa qualitativa que tem o seguinte problema de investigação: quais são os conhecimentos dos professores do ensino básico a respeito dos movimentos de rotação e de translação da Terra? A investigação, em resposta ao problema, se baseia em duas questões de pesquisa: 1) Quais são os conhecimentos dos professores do ensino básico sobre os modelos que tentam explicar a realidade celeste, propostos pelos gregos, por Copérnico e por Kepler? 2) Quais são os conhecimento dos professores acerca de questões relativas ao ensino dos movimentos da Terra, como as provas do movimento, sistemas de referência, a observação do céu?

\section{Metodologia}

A investigação ocorreu por meio da aplicação de um questionário contendo várias questões, sendo somente duas delas selecionadas para este trabalho, uma vez que eram do tipo Likert (ver quadros 1 e 2 anexos) e tratavam da história e do ensino dos movimentos da Terra. Por meio de uma escala de resposta psicométrica para avaliar o nível de concordância frente a um dado enunciado, o professor participante respondeu a respeito dos modelos cosmológicos e sobre questões relacionadas em como se ensinar esses movimentos.

Os enunciados relativos a cada questão foram identificados em artigos científicos e materiais didáticos de Astronomia e de Física, adaptados, classificados e posteriormente submetidos à apreciação de um especialista em Astronomia e aplicados como pré-teste a três professores da população alvo. As críticas e sugestões do grupo foram analisadas e incorporadas.

O método de análise dessas afirmativas apoiou-se nos trabalhos de Manassero e Vázquez (2002), que por sua vez utilizaram o formulário VOSTS (Views on Science-Technology Society) adaptado da pesquisa conduzida por Aikenhead e Ryan (1992). O procedi- 
mento adotado pelos autores, no sentido de maximizar a informação, faz que o participante assinale certo valor de concordância ou discordância do enunciado que alterna entre $1 \mathrm{e}$ 9. Cada proposição do questionário é classificada como adequada, plausivel e simplista seguindo os preceitos de Manassero e Vázquez (2002), em que uma proposição apropriada indica uma opinião correta acerca do tema; uma proposição plausível ainda que não seja totalmente adequada expressa aspectos adequados; e uma proposição simplista demonstra uma visão que não é válida nem plausível.

Manassero e Vázquez (2002), ainda, elaboraram uma métrica para o índice global atitudinal que varia de -1 a 1 . Sendo o índice global atitudinal positivo, a atitude é valiosa, sendo cada vez mais valiosa quanto mais esse índice se aproximar de 1 . Se o índice global atitudinal for negativo, a atitude não é valiosa, sendo menos valiosa quanto mais se aproximar de -1.

Os participantes do questionário foram os professores de Ciências e os de Física da educação básica. O instrumento foi aplicado de forma on-line e em papel para as duas áreas do saber. Foram enviados 247 questionários via on-line com um retorno de 45 deles. Quanto aos questionários em papel, foram entregues 15 exemplares com 11 devoluções. Ao todo, foram obtidos 56 questionários para a análise, ou seja, 23\% do total. A baixa taxa de respostas é um dos inconvenientes do questionário (em geral, entre $25 \%$ a $30 \%$, segundo FORTIN, 2009), mas como as duas questões utilizaram escalas de medida, foi possível identificar algumas características das respostas dos professores.

\section{Resultados}

Os professores participantes responderam a duas questões: Questão 1) Por quase dois mil anos prevaleceu a ideia dos gregos - Aristóteles e Ptolomeu - da Terra estar estática e o Sol e demais astros se movimentando ao redor de nosso planeta. A partir do século XVI, essa ideia foi suplantada - por Copérnico e Kepler - e o Sol passou a ser aceito como centro dos movimentos dos planetas. Em relação aos enunciados abaixo, qual é o grau de acordo com o que pensa sobre essas ideias? Questão 2) Os movimentos da Terra são um dos tópicos mais presentes no estudo da Astronomia no Ensino Fundamental. O assunto é muito relevante, pois esses movimentos estão relacionados com dois intervalos de tempo que organizam a nossa vida: o dia e o ano. Em relação aos enunciados a seguir, qual o seu grau de acordo com o que pensa ser o ensino dos movimentos da Terra?

O objetivo da questão 1 foi investigar quanto os professores participantes conhecem sobre os modelos de interpretação da realidade celeste propostos pelos gregos, por Copérnico e por Kepler. Já o objetivo da questão 2 foi investigar o conhecimento dos professores a respeito de questões pertinentes para ensinar os movimentos da Terra e os fenômenos do dia e da noite e das estações do ano, como as provas dos movimentos da Terra, a questão do referencial e do que é observado a olho nu no céu.

A análise dos dez enunciados referentes à questão 1 indicou que o valor do índice global atitudinal foi de 0,18 . Esse valor representa uma atitude valorativa dos professores, já que o valor é positivo. Contudo, o valor 0,18 está muito aquém de 1 , resultado que vem mostrar que os professores possuem concepções simplistas para com os enunciados da questão 1 . Tal resultado pode ser observado na Figura 1. 
Figura 1: Índice global das respostas dos professores para a questão 1.

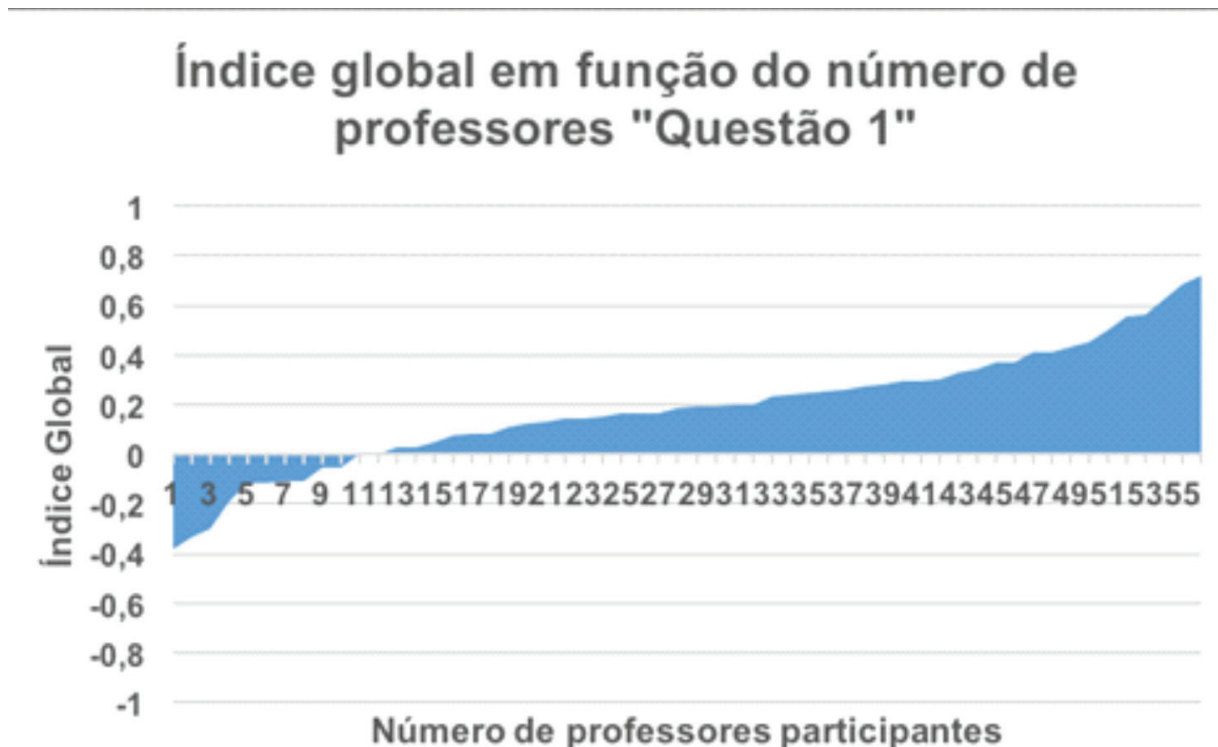

Fonte: Autores

A análise dos sete enunciados referentes à questão 2 indicou que o índice global atitudinal foi de $-0,08$. Esse valor negativo mostra que a maior parte das respostas está na parte negativa do gráfico, indicando que há uma tendência bastante simplista dos professores para com as proposições da questão 2. Isto pode ser confirmado por meio da Figura 2.

Figura 2: Índice global das respostas dos professores para a questão 2.

\section{Índice global em função do número de professores "Questão 2"}

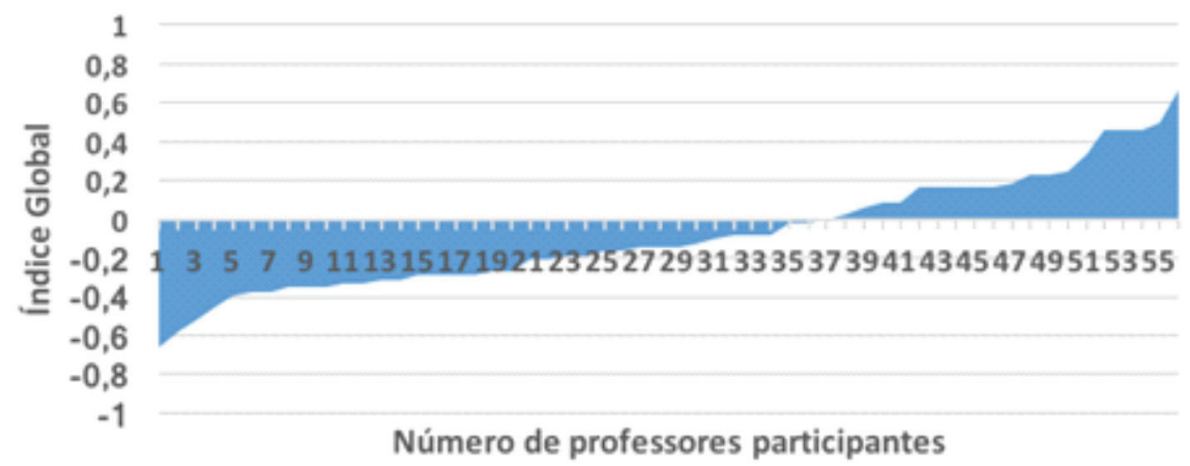

Fonte: Autores 


\section{DiscuSSÃo}

Por meio das Figuras 1 e 2 observa-se que os professores tendem a possuir concepções simplistas sobre os enunciados. Mesmo para aqueles enunciados que apresentaram resultados positivos, nota-se que muitos professores obtiveram índices bem distantes de 1 , que seria o maior e melhor de todos. Tal resultado indicou que há professores com dúvidas e/ou desconhecimento de conceitos, de fatos históricos e de observação do céu.

Os dados apontaram ainda que os professores de Ciências possuem menores conhecimentos em Astronomia, quando comparados com os professores de Física. Essa afirmação vem do fato de que na questão 1 , o valor do índice global atitudinal para os professores de Física foi de 0,21, e para os professores de Ciências foi de 0,16. Na questão 2, verifica-se que o valor do índice global atitudinal para os professores de Física foi de $-0,07$ e para os professores de Ciências foi -0,12. Esse resultado é explicado pelo fato de que os professores que ensinam Ciências são formados em Biologia ou em Ciências Biológicas (PUZZO, TREVISAN, LATARE, 2004; LEITE, HOSOUME, 2007), cursos que, em geral, não possuem Astronomia no currículo.

A questão 1, apesar de ter enunciados de cunho mais histórico, refere-se a conhecimentos básicos que os professores de Ciências (e os de Física também) deveriam possuir, já que são temas, em geral, presentes nos Livros Didáticos de Ciências quando se estuda a Terra e seus movimentos, o dia e a noite e as estações do ano.

$\mathrm{Na}$ questão 2, verifica-se a mesma situação, pois há sete enunciados que deveriam ser de conhecimento básico dos professores de Ciências e de Física, mas não são. Nota-se ainda certo desconhecimento dos professores com a questão das provas dos movimentos da Terra e com o conceito de referencial.

De maneira geral, os resultados apontaram que os professores possuem dificuldades de entendimento com relação a alguns temas da Astronomia que estão presentes na sala de aula, temas que estão diretamente ligados aos fenômenos diários da vida das pessoas.

Essas questões fazem que se concorde com Albanese et al. (1997 apud SEBASTIÀ, 2004, p. 9) quando ponderam que "o conhecimento das regularidades astronômicas é uma peça fundamental no processo de construção e validação dos modelos astronômicos, já que, como se pode justificar o modelo Sol-Terra se se desconhecem as regularidades que devem ser explicitadas?"

Para amenizar essa situação, se poderia introduzir temas básicos de Astronomia em cursos de licenciatura em Ciências da Natureza e de Matemática e oferecer cursos de formação continuada em Astronomia para professores. Ao concordarmos com Martins et al. (1999, p. 32) que "antes que uma estória acerca de determinado fenômeno possa ser contada na sala de aula, é preciso construir os recursos que serão utilizados nesse processo" acreditamos ser importante iniciar o ensino da Astronomia privilegiando a percepção primeira do aluno, ou seja, iniciar os estudos do dia e da noite e das estações do ano por aquilo que o aluno observa na natureza para este criar possíveis explicações dos dados observados em diferentes referenciais. 
Nessa trajetória, a mediação do professor terá um papel fundamental, assim como a utilização da História da Ciência para formalizar e facilitar a compreensão dos conceitos que serão trabalhados.

\section{ConsideraÇões FinAis}

Os dados apontaram que os docentes aparentam ter ideias equivocadas sobre os movimentos da Terra, como já evidenciados por Bisch (1998), quando afirma que os professores possuem as próprias concepções e os próprios modelos a respeito dos astros, do céu e do universo.

Notou-se ainda que os professores parecem ter pouca informação sobre o que conseguiam e não conseguiam explicar nos modelos cosmológicos dos gregos, de Copérnico e de Kepler, além de darem pouca importância para a observação direta dos fenômenos e movimentos celestes, como pode ser visto por meio da análise das questões 1 e 2 do questionário.

Assim, a proposta de se iniciar o estudo dos movimentos da Terra e dos fenômenos do dia e da noite e das estações do ano por meio de uma visão topocêntrica não tem por finalidade retornar a teorias antigas para questionar o que se acredita hoje ser correto pela Ciência, mas ensinar de forma a favorecer que os alunos se apropriem do modelo científico aceito.

A ideia é utilizar uma visão de universo que faz parte do senso comum das pessoas como uma ponte para conduzir o aluno ao conhecimento moderno dos conceitos astronômicos. Afinal, como diz Kuhn (1995, p. 21), "teorias obsoletas não são acientíficas em princípio, simplesmente porque foram descartas". Teorias antigas têm ainda sua validade que, nesse caso, podem ser utilizadas para dar suporte ao aprendizado das teorias astronômicas modernas. Em síntese, entendemos ser preciso melhorar a explicação do modelo aceito, aproximando "posições que se encontram separadas por abismos conceituais" (MARTINS et al., 1999, p. 26).

Finalizamos este trabalho, sem a intenção de esgotar o tema, apresentando uma citação de Martins (2016, p. 18), que consideramos muito pertinente para o momento:

[...] a ciência não é uma "verdade", mas algo que se aceita em certa época porque parece bem fundamentado em observações, cálculos, argumentos, discussões. Quando ensinamos apenas os resultados da ciência, e não o processo científico que levou à gradual formação e aceitação das teorias, estamos apenas transmitindo um conjunto de crenças, e não um ensino científico. Quando fazemos isso, estamos doutrinando os estudantes e não transmitindo uma noção correta sobre o que é a astronomia como ciência.

\section{REFERÊNCIAS}

AIKENHEAD, G. S. RYAN, A. G. The development of a new instrument: "Views on science-technology-society" (VOSTS). Science \& Education, v. 76, n. 5, p. 477-491, 1992. 
ALBANESE, A.; DANHONI NEVES, M. C.; VICENTINI, M. Models in science and in educational: a critical review of research on student's ideas about the earth and its place in the universe. Science \& Education, v. 6, n. 6, p. 573-590, 1997.

BARRA, E. S. O. et al. A função do dogma na investigação científica de Thomas Kuhn, Curitiba: Ufpr - Schla, 2012, 73 p. (Textos Filosóficos na Sala de Aula). Tradução de Jorge Dias de Deus. Disponível em: $<$ http://www.filosofia.seed.pr.gov.br/arquivos/File/traduzindo/kuhn_funcao_dogma_na_investigacao_cientifica.pdf $>$. Acesso em: 3 out., 2015.

BAXTER, J. Children's understanding of familiar astronomical events. International Journal Science Education, v. 11, p. 502-513, 1989.

BEN-DOV, Y. Convite à física, Rio de Janeiro: Jorge Zahar Editor Ltda., 1996, 152 p. Tradução de Maria Luiza X. de A. Borges; Revisão técnica de Henrique Lins de Barros.

BISCH, S. M. Astronomia no ensino fundamental: natureza e conteúdo do conhecimento de estudantes e professores, 1998, 301s. Tese (Doutorado) - Curso de Educação, Faculdade de Educação, Universidade de São Paulo, São Paulo, 1998.

CASTRO, A. C.; SCHIEL, D. O céu e a Terra. In: SCHIEL, D.; ORLANDI, A. S. Ensino de Ciências por Investigação, São Carlos: Universidade de São Paulo, 2009, p. 87-111. CDCC - USP. Disponível em: <http://www.cdcc.usp.br/maomassa/livros ensinodeciencias.html >. Acesso em: 11 abr., 2016.

CHIRAS, A.; VALANIDES, N. Day/Night cycle: mental models of primary school children. Science Education International, v. 19, n. 1, p. 65-83, mar., 2008.

FORTIN, M-F. Fundamentos e etapas do processo de investigação. Lusodidacta, Portugal, 2009.

KIKAS, E. The impact of teaching student's explanations of astronomical phenomena. Psychology Of Language And Communication, v. 1, n. 2, p. 45-52, 1997.

KOYRÉ, A. Galileu e a revolução científica do século XVII. In: KOYRÉ, A. Estudos de História do Pensamento Científico, 3. ed., Rio de Janeiro: Forense, 2011, cap. 11, p. 197213.

KUHN, T. A estrutura das revoluções científicas, 3. ed., São Paulo: Editora Perspectiva, 1995, 257p. Tradução: Beatriz Vianna Boeira e Nelson Boeira.

LANGUI, R. Ideias de senso comum em astronomia, 2016. Disponível em: $<\underline{\text { http: } / / \text { www. }}$ telescopiosnaescola.pro.br/langhi.pdf>. Acesso em: 18 mai., 2016.

LEITE, C.; HOSOUME, Y. Os professores de ciências e suas formas de pensar a astronomia. Revista Latino-americana de Educação em Astronomia - Relea, n. 4, p. 47-68, 2007. Disponível em: <http://www.relea.ufscar.br/index.php/relea $>$. Acesso em: 19 abr., 2012.

MANASSERO, M. A.; VÁZQUEZ, A. Instrumentos y métodos para a evaluación de las 
actitudes relacionadas con la ciencia, la tecnología y la sociedad. Enseñanza de Las Ciencias, v. 1, n. 20, p. 15-27, 2001.

MARTINS, I; OGBORN, J.; KRESS, G. Explicando uma explicação. ENSAIO - Pesquisa em Educação em Ciências, v. 1, n. 1, 1999.

MARTINS, R. A. História da Astronomia e Ensino. In: ENCONTRO BRASILEIRO DE ENSINO DE ASTRONOMIA, 8. São Paulo. Anais... São Paulo: Pontifícia Universidade Católica de São Paulo. Disponível em: http://www.ghtc.usp.br/server/pdf/ram-VIII-EBEA. PDF. Acesso em: $1^{\circ}$. de ago., 2016.

PUZZO, D.; TREVISAN, R. H.; LATARE, C. J. B. Astronomia: a investigação da ação pedagógica do professor. In: ENCONTRO NACIONAL DE PESQUISA EM ENSINO DE FÍSICA, 9, 2004, Jaboticatubas - Mg. Anais... Jaboticatubas: Universidade Federal de Minas Gerais, 2004, p. 1-13. Disponível em: $<$ http://www.sbf1.sbfisica.org.br/eventos/epef/ $\underline{\mathrm{ix} />}$. Acesso em: 11 out., 2009.

SEBASTIÀ, B. M. La enseñanza/aprendizaje del modelo Sol-Tierra: análisis de la situación actual y propuesta de mejora para la formación de los futuros profesores de. Revista Latino-americana de Educação em Astronomia - Relea, n. 1, p. 7-32, 2004.

VOSNIADOU, S.; BREWER, W. F. Mental models of the Earth: a study of conceptual change in childhood. Cognitive Psychology [s.i.], n. 24, p. 535-585, 1992.

\section{Dados dos Autores}

Michel Paschini Neto

Doutor em Educação pela Universidade Metodista de Piracicaba. Piracicaba/SP - Brasil. michelpaschini@icloud.com

\section{Maria Guiomar Carneiro Tommasiello}

Doutora em Tecnologia Nuclear pela Universidade de São Paulo. Piracicaba/SP - Brasil. mgtomaze@unimep.br

Submetido em: 22-12-2016

Aceito em: 20-2-2017 


\section{ANEXOS}

Quadro 1 - Questionário aplicado aos professores: questão 1

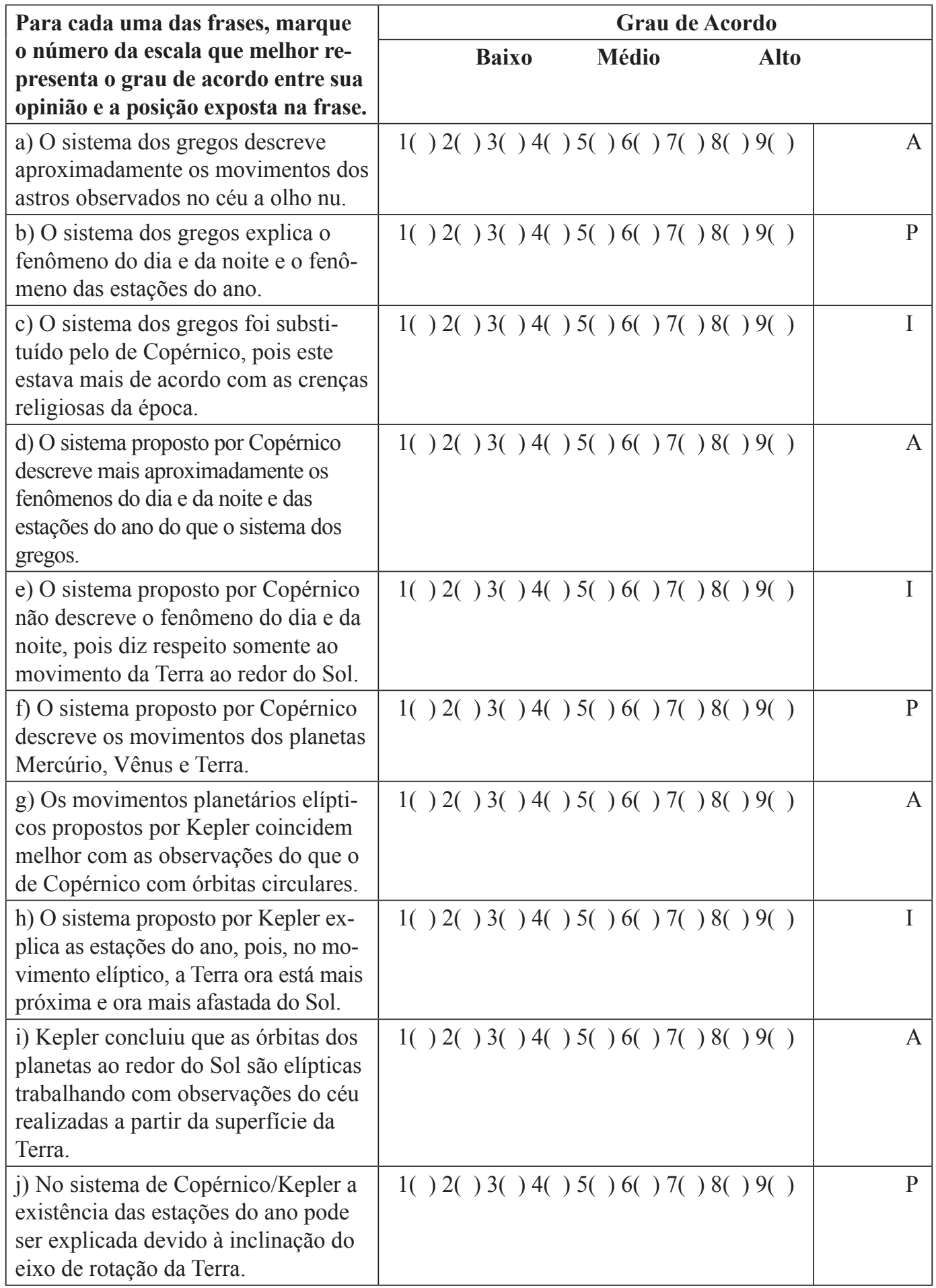


Quadro 2 - Questionário aplicado aos professores: questão 2

\begin{tabular}{|c|c|c|}
\hline \multirow{2}{*}{$\begin{array}{l}\text { Para cada uma das frases, marque o núme- } \\
\text { ro da escala que melhor representa o grau } \\
\text { de acordo entre sua opinião e a posição } \\
\text { exposta na frase. }\end{array}$} & \multicolumn{2}{|l|}{ Grau de Acordo } \\
\hline & Médio $\quad$ Alto & \\
\hline $\begin{array}{l}\text { a) Podemos afirmar aos alunos que o dia e a } \\
\text { noite são provas do movimento de rotação da } \\
\text { Terra e que as estações do ano são provas do } \\
\text { movimento de translação da Terra. }\end{array}$ & 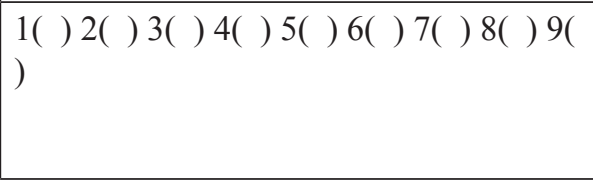 & $\mathrm{I}$ \\
\hline $\begin{array}{l}\text { b) Podemos explicar aos alunos que o movi- } \\
\text { mento de "laçada" que os planetas descrevem } \\
\text { no céu acontece porque a Terra está orbitando } \\
\text { o Sol. }\end{array}$ & 1( ) $2($ ) $3($ ) $4($ ) $5($ ) $6($ ) $7($ ) $8($ ) 9( & $\mathrm{P}$ \\
\hline $\begin{array}{l}\text { c) Observando o céu a olho nu, podemos } \\
\text { dizer aos alunos que não há fenômeno algum } \\
\text { que comprove que a Terra se move. }\end{array}$ & 1( ) $2($ ) 3( ) 4( ) 5( ) 6( ) 7( ) 8( ) & $\mathrm{A}$ \\
\hline $\begin{array}{l}\text { d) Podemos ensinar aos alunos que o Sol } \\
\text { nasce no leste e se põe no oeste. }\end{array}$ & 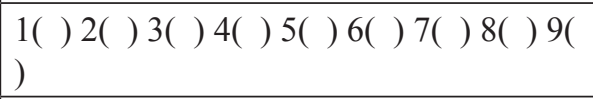 & $\mathrm{P}$ \\
\hline $\begin{array}{l}\text { e) É possível explicar para os alunos o dia e a } \\
\text { noite a partir de um observador na superfície } \\
\text { da Terra. }\end{array}$ & 1( ) $2($ ) 3( ) 4( ) 5( ) 6( ) 7( ) 8( ) & A \\
\hline $\begin{array}{l}\text { f) Ao observarmos o céu, podemos afirmar } \\
\text { aos alunos que um avião, um pássaro, a Lua e } \\
\text { o Sol estão se movendo em relação a um ob- } \\
\text { servador parado na superfície da Terra. }\end{array}$ & 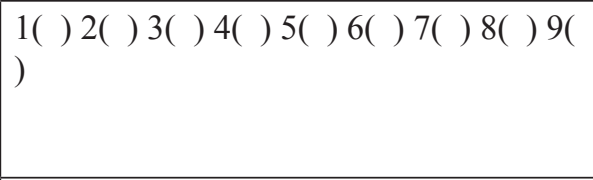 & $\mathrm{A}$ \\
\hline $\begin{array}{l}\text { g) É possível afirmar aos alunos que se } \\
\text { estou sentado em um banco, estou parado } \\
\text { em relação a uma pessoa que passa andando } \\
\text { ao meu lado, porém, em relação às estrelas, } \\
\text { estou em movimento. }\end{array}$ & 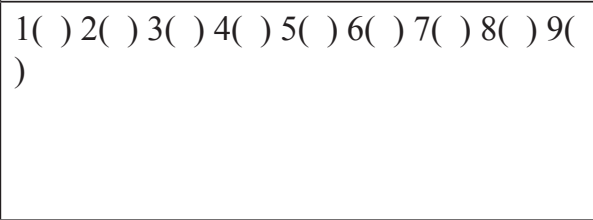 & A \\
\hline
\end{tabular}

